\title{
Huellas del yo en Historia del pelo de Alan Pauls
}

\author{
Footprints of the self in Historia del pelo (A history of hair) by Alan Pauls
}

\author{
María Luisa Martínez M. \\ Universidad de Concepción, Región del Bío Bío, Chile \\ Contacto:marmartinez@udec.cl \\ https://orcid.org/0000-0002-9962-0132
}

\begin{abstract}
Resumen
Historia del pelo de Alan Pauls (2010) revela las misteriosas conexiones entre los grandes relatos políticos y los pequeños hechos cotidianos, en apariencia insignificantes, que constituyen la vida. El relato de la dictadura argentina se expresa a partir de una narración autoficcional en la que un elemento banal, el pelo, adquiere un valor icónico; este representa una época, un estilo, un espacio social y hasta étnico. La humanidad inscrita en el pelo representa el carácter político de la cultura, el que impone una determinada época o un cierto espacio, pero también la proximidad con vidas irreconocibles, al margen de los grandes relatos históricos. Los personajes de la novela de Pauls señalan un recorrido marcado por la soledad, la enfermedad y la amenaza de la muerte. Las huellas que el pelo va trazando en el cuerpo se inscriben como el relato de una memoria subjetiva que se refleja en la presencia de la figura animal, la no-persona, que nos interpela y cuestiona.
\end{abstract}

Palabras clave: Historia del pelo; Alan Pauls; Novela argentina; Dictadura.

\begin{abstract}
Historia del pelo by Alan Pauls (2010) reveals the mysterious connections between the great political stories and the seemingly irrelevant small everyday events that make up life. The story of the Argentinian dictatorship is expresses from a self-fictional narrative where an insignificant element, hair, acquires an iconic value. It represents an era, a style, a social and even ethnical space. The humanity inscribed in hair represents the political character of culture, which imposes a certain era or space, but also the proximity to unrecognisable lives, outside the great historical stories. The characters in Pauls' novel show a path marked by loneliness, illness, and the threat of death. The traces that hair imprints on the body are inscribed as the tale of a subjective memory that is reflected in the presence of the animal figure, the non-person, which addresses and questions us.
\end{abstract}

Keywords: Historia del pelo; Alan Pauls; Argentine novel; Dictatorship.

Recibido: 10.10 .18

Aceptado: 21.04.2019 


\section{Introducción}

Alan Pauls explora la historia argentina de los años setenta del siglo XX, a partir de una escritura que indaga en las posibles vías de acceso al proceso de memorialización del pasado en la trilogía compuesta por Historia del llanto (2007), Historia del pelo (2010) e Historia del dinero (2013). La reconstrucción de la historia latinoamericana reciente, marcada por procesos dictatoriales y por el posterior testimonio de las víctimas de los gobiernos totalitarios, ha sido ampliamente abordada desde el pensamiento teórico y crítico de estas latitudes; la literatura latinoamericana reciente se instala en esta corriente y surge como expresión autoficcional de las experiencias del horror y de la violencia. Historia del pelo, como las otras dos novelas de la trilogía de Pauls, manifiesta la preocupación del autor por acercarse al relato y al mito de la dictadura argentina a partir de una posición política, ética y estética que no solo resquebraja la seriedad que se le exige a la narración de un período particularmente convulso, sino que además señala la inestabilidad del imaginario que se desprende de lo privado y lo íntimo. La novela de Pauls se centra en una obsesión aparentemente banal, el pelo, para señalar los alcances que este tiene como marca y como huella. El pelo tiene, así, un valor icónico y político en la novela de Pauls; representa una época, un estilo, un espacio social y hasta étnico. Pero la huella que el pelo traza va más allá, ya que marca la humanidad de los personajes y los signos territoriales que en ella se inscriben. El autor del texto, desde la narración autoficcional, cuestiona la humanidad inscrita en el pelo y reflexiona sobre el carácter político de la cultura; no solo en cuanto a la politización que imponen determinadas épocas y espacios, sino que más allá: en relación con “[...] los marcos de inteligibilidad que hacen reconocible una vida como humana, como persona y como vida vivible en contraposición a los cuerpos irreconocibles social y políticamente, en el arco que va del animal a la no-persona" (Giorgi, 2014, p. 16).

Historia del pelo revela las misteriosas conexiones entre los grandes relatos políticos y los pequeños hechos cotidianos, en apariencia insignificantes, que constituyen la vida. La novela señala la forma en que el protagonista, "un 
loco del pelo", se desplaza desde el territorio asignado a la humanidad e ingresa hacia uno nuevo, más oscuro, más precario, pero también más enriquecedor. La presencia animal asoma espectralmente en el texto para señalar un devenir en el que ella es solo un segmento, una llave hacia la involución que atraviesa el protagonista de la novela. La autoficción de Pauls se centra en las subjetividades de un yo cambiante, contradictorio y heterogéneo; en ese tránsito, Curtius, el perro del protagonista, señala un espejo en el que se visualiza un mundo espectral, la amenaza de la enfermedad y la muerte que hombres y animales compartimos.

\section{"Las marcas están ahí, nítidas como tatuajes o huellas digitales"}

Manuel Alberca señala que la literatura autobiográfica expande sus dominios durante la década de 1970, momento que coincide con el auge de los relatos autoficcionales. Los lindes entre lo real y lo inventado conviven en un género que permite la imaginación de vidas posibles; la contradictoria naturaleza de un autor que puede confundirse con el personaje de la obra, aunque claramente no sean el mismo, permite el acercamiento a una historia no vivida desde el lugar protagónico asignado a los grandes relatos testimoniales:

El autor de autoficciones no se conforma sólo con contar la vida que ha vivido, sino en imaginar una de las muchas vidas posibles que le podría haber tocado en suerte vivir. De manera que el escritor de autoficciones no trata sólo de narrar lo que fue sino también lo que pudo haber sido. Esto le permite vivir, en los márgenes de la escritura, vidas distintas a la suya. (Alberca, 2007, p. 33)

La dictadura argentina, que se inicia con el golpe de Estado en 1976 y trae como consecuencia el gobierno de Jorge Rafael Videla que culmina en 1983, recorre tangencialmente la narración de Historia del pelo. La trilogía de Pauls, como ha señalado Brigitte Adriaensen a propósito de Historia del llanto, incorpora la ironía, un recurso excluido y prácticamente impensable en términos éticos para referir el dolor colectivo desde el atentado a las torres gemelas en septiembre de 2001: "Así el protagonista defiende sobre todo la idea del dolor desde el dolor" (2017, p. 62). Historia del pelo prosigue la experimentación con los alcances de la 
utilización de la ironía como recurso para desenmascarar la verdad de los discursos colectivos desde una posición subjetiva que reflexiona sobre la politización de la memoria y, fundamentalmente, del propósito neoliberal de un proyecto anclado en la idea de felicidad. El protagonista de la novela no es una víctima del régimen de Videla, tampoco es uno de los héroes de la resistencia; la narración se centra en un período que es percibido desde el egotismo de un niño, luego un hombre, a quien solo parece preocuparlo su pelo, pero el texto delinea cómo incluso tras una aparente frivolidad se esconden las consecuencias de un período que afecta a una colectividad, pero que siempre se vive desde la experiencia personal. La trilogía de Pauls se centra en microhistorias narradas en clave irónica, en una reducción de escala propia de la narración historiográfica contemporánea. Cecilia González observa un diálogo entre arte e historia argentina en los textos de Pauls y señala que el autor entra en la época de los setenta a partir de esa indagación en lo microscópico que permite "[...] postular de entrada la dimensión política tanto de lo íntimo y lo privado como de lo público e, incluso, para decirlo con un término que vuelve en Historia del llanto, su reversibilidad" (2017, p. 11). Ilse Logie plantea que la trilogía de Pauls se sitúa a medio camino entre la novela y el ensayo, y que se presenta como

[...] un testimonio de segunda mano que se escribe irónicamente en tercera persona, la tercera persona de la autoficción, incompatible por principio con el pacto de lectura que rige la adscripción genérica testimonial: el de la obligación de no transigir con la verdad. (2013, p. 172)

El protagonista de Historia del pelo, en quien habitan huellas del autor del texto a partir del pacto de lectura que se establece con un relato autoficcional, es testigo de la turbulenta década del setenta. Sin embargo, su tránsito por los conflictos sociales es vivido desde el problema de tener pelo lacio, lo cual se opone a las marcas del estilo representativo del grupo hegemónico, “[...] ya que su clase de origen, como empieza a decirse entonces, sólo se concibe a sí misma con el pelo lacio y condena cualquier otro tipo de pelo al ostracismo que merecen ciertas anomalías étnicas" $(28)^{1}$. El protagonista de Historia del pelo es marginal al gran relato político de la época y el autor del texto se centra en la historia 
menor de su obsesión para resemantizar, como señala Logie, “[...] esos años desbordantes de significados" (2013, p. 170). El conflicto de la novela señala la imposibilidad de la escritura y de la producción estética en general para referir un período marcado por el dolor. El texto presenta un yo que se sitúa en el lugar de testigo de un conflicto que lo excede y que él solo "[...] percibe de manera oblicua, en una segunda instancia" (24) en las señas que el pelo porta sobre la política de la época, la que se inscribe y lee en las marcas íntimas y subjetivas del yo: “¿Qué es la época? ¿A qué se reduce, cuánto dura una época sin mentir o evaporarse si no cristaliza en un nombre propio, un estilo personal, un cuerpo marcado por señas particulares y por huellas?" (27). La reflexión que la novela postula se centra en la contradicción entre el gran discurso testimonial, el de las víctimas del dolor, y la cotidianidad de vidas excluidas de la heroicidad — pero que también son afectadas por las huellas de una época signada por el trauma-; de los testigos mudos de una historia común, en palabras de Rancière, que se desplazan sin encontrar un lugar de pertenencia en medio de la violencia ${ }^{2}$. La ironía que se esconde en la obsesión por el pelo banaliza el dolor ajeno y permite cuestionar la humanidad de los personajes, quienes expresan el dolor, la marginalidad y la enfermedad de vivir en las marcas que la humanidad señala; pero hombres y animales comparten ciertas señas, por ejemplo el pelo. Esa constatación niega el hiato que se expresa en la historia de las relaciones entre el hombre y el animal, una historia que condena a ambas figuras a una soledad insalvable. Giorgio Agamben señala que

[...] en nuestra cultura, el hombre - lo hemos visto - ha sido siempre el resultado de una división, y, a la vez, de una articulación de lo animal y lo humano, en la cual uno de los dos términos de la operación era también lo que estaba en juego. (2006, p. 167)

La reificación humana contemporánea tras el Holocausto ${ }^{3}$ moviliza la posición animal hacia una nueva zona y sitúa a "[...] cualquier sujeto que de un modo u otro no se ajuste al concepto dominante de hombre que se ha construido históricamente" (Yelin, 2008, p. 3) en un proceso de animalización que lo despoja de su identidad. La deshumanización no se aplica solo al grupo afectado por el dolor, sino también a quienes son testigos de él y participan — con su mudez 
e indiferencia - de los códigos de violencia. La relación de semejanza con la imagen del matadero se hace evidente y es fundamental en la narrativa de un país que tiene entre sus textos fundacionales el relato homónimo de Esteban Echeverría (1871). Historia del pelo comienza con el protagonista entrando a una peluquería desierta donde le lavan el pelo; ahí, a merced de la chica que lo atiende, incómodo y con dolor en las cervicales, “[...] lo inquieta un poco la desaprensión con que su garganta parece ofrecerse al tajo del primer degollador que le salga al cruce" (9). La indefensión en la que se encuentra ante la experiencia siempre demoledora de visitar por primera vez una peluquería es análoga a la desvalidez de los animales que son conducidos al matadero y, finalmente, a la experiencia del Holocausto, la que se erige como el referente obligado del mal. La reificación filosófica del animal que plantea Descartes es reemplazada por la reificación humana contemporánea tras el Holocausto y abre la discusión ética y estética respecto de los límites entre reinos que han compartido las mismas experiencias a lo largo de la historia, entre ellas la muerte, que siempre se vive desde la subjetividad del yo:

Entre mil novecientos cuarenta y dos y mil novecientos cuarenta y cinco varios millones de personas encontraron la muerte en los campos de concentración del Tercer Reich: solamente en Treblinka murieron más de un millón y medio, tal vez hasta tres millones. Se trata de cifras que aturden. Solamente tenemos una muerte cada uno. Solamente podemos entender las muertes ajenas una por una. En abstracto tal vez podamos contar hasta un millón, pero no hasta un millón de muertes. (Coetzee, 2005, p. 70)

Yo Tsun, el personaje de "El jardín de senderos que se bifurcan" de Borges (1980), advierte que solo en el presente suceden los hechos y que "todo lo que realmente pasa me pasa a mí". Las experiencias de "innumerables hombres" se incorporan desde el yo, el que se rige por sus propias lógicas, criterios y dolores. El protagonista de Historia del pelo parece llegar al mismo descubrimiento por extrañas vías, porque lo que define su posición ante el contexto de opresión es percibido desde el dolor particular de vivir el calvario fetichista de su pelo. El significado real del estilo afro que surge como un emblema político que se define en el lenguaje icónico de una moda solo es capaz de comprenderlo treinta años después, cuando ve Black panther newsreel, la película de Agnès Varda (1968). 
La insurrección que caracteriza el paso de una época a otra la percibe al inicio solo tangencialmente, porque lo que predomina en él es la sensación de exclusión del estilo dominante de un movimiento que experimenta a través del complejo de tener un pelo que no se ajusta al canon libertario que el afro promulga. Decide convertirse entonces a la moda imperante, aunque no lo logra; por años carga, así, con el fracaso de ese intento fallido que se expresa en el nido revuelto que le crece en la cabeza como resultado de la práctica de no lavarse el pelo para emular el crespo de los Panteras Negras:

De un día para el otro se convierte al afro, a ese afro pobre, enclenque, por demás inconvincente, mucho más próximo al desvalimiento aturdido en el que despierta un pelo no del todo limpio tras una larga noche de cama que al aplomo orgulloso, la imagen de poder, la dignidad enhiesta que irradian cinco años antes, cuando efectivamente reclaman la libertad de Huey Newton, y treinta después, cuando él ve la película de Agnès Varda que los ha documentado en pleno reclamo, las cabelleras de los Panteras Negras. (25)

La heroicidad de la época se vive desde la subjetividad de la experiencia personal; el único modo posible, parece decir el autor, para acercarse a determinados momentos que solo se pueden comprender a partir de las marcas y huellas que se imprimen en el cuerpo: el espacio de la escritura de esos signos que el tiempo va depositando en el pelo, las uñas, el peso corporal, etc. Thomas Mann señala en La montaña mágica que el hombre vive su vida individual y, además, participa de la de su época; cuando esta última se representa desesperanzada y sin objetivos, vacía, “[...] esta influencia más allá del alma y de la moral, se extenderá hasta la parte física y orgánica del individuo" (1951, p. 773). La novela de Pauls aborda una época que los personajes viven de manera traumática, como un recorrido marcado por la fragilidad constante; un camino inscrito fundamentalmente en el cuerpo, el que constituye el eje de una agresión que, en definitiva, es la de vivir. La marginalidad del centro, la vida desde la periferia, es central en la narrativa de Pauls y se disfraza de frivolidad en la pasión obsesiva que el pornógrafo siente por Úrsula en El pudor del pornógrafo (1984), pasión que lo consume y lo fantasmagoriza en la medida en que la relación misma es 
fantasmal; también parece ser superficial la monstruosidad del cuerpo que aqueja sorpresivamente al escritor en Wasabi (1994), quien somatiza la imposibilidad de la escritura a través de la piel. Otra aparente ligereza parece el amor vivido como enfermedad y tormento entre Sofía y Rímini, un amor que reaparece continuamente como espectro y pesadilla en El pasado (2003). La enfermedad y el cuerpo son constantes en la obra de Pauls. La primera se expresa en el segundo y desde allí se sufre. Teresa Orecchia plantea que el cuerpo en Pauls es objeto de una monstruosidad, como sucede con el espolón que le crece al escritor en Wasabi y que señala metafóricamente la deformidad de la escritura que la novela postula; o como sucede con el amor obsesivo de los protagonistas de El pasado, quienes insisten en actualizar una pasión que ya ha terminado y que solo existe en el presente como síntoma de una enfermedad que se expresa en la disolución de las fronteras de un yo que

[...] se disgrega en la identificación final de los amantes, expresa en la metáfora del desangrarse, imagen de un tiempo que se anula en la continuidad monstruosa de un presente absoluto y de un cuerpo que ya no reconoce sus propios límites. $(2013$, p. 8 )

La enfermedad presente en Historia del pelo consiste en el despertar a la conciencia de que tener pelo se traduce en marca de la decepción. El atributo de poseer un pelo lacio que el protagonista desdeña en su niñez se resuelve en un continuo extrañamiento de esa propiedad que luego añora y que solo existe como un fantasma del pasado. El lacio, tras la experiencia con el afro que intenta cultivar, no vuelve nunca más y el calvario de peregrinar por diferentes peluquerías en búsqueda del imposible, de la felicidad y de la paz que otorga un pelo perfecto es finalmente la condena del protagonista, la huella de la decepción. Tener pelo es un verdadero castigo, porque exige la preocupación por cuidarlo, el temor de perderlo, la insatisfacción de nunca alcanzar el ideal o solo atisbarlo. Esta obsesión se despliega a lo largo de la novela a través de su relación con Monti, un lejano, querido y a la vez envidiado amigo de la infancia; con Celso, el peluquero ideal, un artista del pelo; y con el veterano de guerra, quien vive exiliado en París hasta que regresa a Buenos Aires a encontrar y perder su lugar 
en el mundo. Estos cuatro personajes se encuentran y desencuentran en la novela, y son los diferentes rostros del mismo tránsito marginal por la historia argentina. Y el eje conector de estos cuatro rostros, de una misma historia fragmentada, es la legendaria peluca teñida con el valor mítico de haber pertenecido a Norma Arrostito, la guerrillera implicada en el secuestro y posterior asesinato de Pedro Eugenio Aramburu en $1970^{4}$.

\section{“Así, esclavo del pelo, quién sabe, hasta reventar. Pero incluso entonces. ¿O no ha leído que...? ¿No les crece el pelo también a...? ¿O eran las uñas?"}

La novela de Pauls se narra desde un presente que indaga en la memoria a partir de la relación del protagonista con su pelo, el que otorga una identidad, que acompaña la certeza de nuestra finitud y que se vincula, por consiguiente, estrechamente con la muerte. El protagonista de la novela no tiene nombre, un elemento relevante. Luz Aurora Pimentel señala que el nombre es el "[...] centro de imantación semántica de todos sus atributos" (2005, p. 63); en tal sentido, la omisión del nombre del protagonista es significativa, porque determina la supresión de la carga (estereotipos sociales, sexuales, étnicos, etc.) que los nombres ejercen sobre la lectura que se establece a partir de ellos. El nombre opera como una voz de ultratumba que se sospecha y que se rechaza de acuerdo con la noción de prosopopeya señalada por Derrida, quien plantea que "[...] ser llamado, oírse nombrar, recibir un nombre por vez primera es quizá saberse mortal e incluso sentirse morir" (2008, p. 37). La supresión del nombre del narrador (una falta de referente que es compartida por otras escrituras del yo latinoamericanas de las últimas décadas) señala un distanciamiento del conocimiento del duelo que el nombre implica; además, este no se refiere solo a la muerte física y real, sino también a la muerte a través de una identidad fijada, establecida, inmutable, molar, que sella categorías y limita los alcances de la vida. La experiencia de poseer y recibir un nombre es semejante a la experiencia de pérdida del rostro, que acecha permanentemente en la novela de Pauls. Historia del pelo comienza con la importancia que el protagonista otorga al rostro:

No importa si lo que aparece es un paisaje, un paredón comido por 
una enredadera, una avenida que hormiguea de gente, una manada de animales, el bendito portón de la fábrica de los hermanos Lumière la primera imagen siempre es una cara. La cara es el fenómeno por excelencia, el único objeto de adoración para el que no hay defensa ni remedio. (10)

La novela presenta la disolución del rostro en la medida en que los personajes van despojándose paulatinamente de aquello que constituye su supuesta humanidad. El yo se diluye en otros rostros, los de los personajes que convergen y divergen en la trama. Gabriel Giorgi señala en Formas comunes. Animalidad, cultura, biopolítica que las escrituras del yo en contagio con el mundo animal evidencian "[...] que la vida es irreductible a un yo, que ese bios que el impulso autobiográfico quiere siempre reapropiar bajo el signo de una subjetividad una firma, una 'persona' en el sentido teatral y jurídico del término- se revela insumiso" (2014, p. 37). Historia del pelo, bajo la apariencia de la superficialidad del pelo, aborda la desterritorialización de cuatro personajes que se insertan en la historia argentina desde diferentes ángulos de exclusión del gran relato político de la época, pero que materializan sus consecuencias en la enfermedad de vivir precariamente, sin el amparo protector del mito, el que es satirizado en el texto. El protagonista, Monti, Celso y el veterano de guerra tienen su espejo sombrío en Curtius, el perro que aparentemente es insignificante respecto del relato central que la novela narra, pero que cumple la función fundamental de señalar que las escrituras del $\mathrm{yo}^{5}$ reformulan lo íntimo y lo autobiográfico, y que "[...] en estos recorridos, literatura y vida se enlazan bajo el signo del animal: del rumor, el afecto, el impulso del animal que habita los cuerpos" (Giorgi, 2014, p. 39). Los animales se asoman en los textos latinoamericanos recientes y desde allí, espectralmente, emergen para cuestionar nuestro orden precario. La monstruosidad que el animal representa para el hombre se alía con otras alteridades en la narrativa latinoamericana de las últimas décadas, por ejemplo la marginalidad, la enfermedad y la muerte. Las escrituras del yo indagan en el reflejo que los animales señalan respecto de nuestra soledad esencial, porque, como plantea Gastón Bachelard: "El escritor sabe por instinto que todas las agresiones, vengan del hombre o del mundo, son animales. Por muy sutil que 
sea una agresión del hombre, por muy indirecta, camuflada y construida, revela orígenes inexpiados" (2000, p. 57).

La amistad entre Monti y el protagonista de Historia del pelo revela la trascendencia que el rostro posee en la constitución de la identidad y en la liberación que el alejamiento del propio rostro otorga. Derrida señala que “[...] allí donde hay mal, hay rostro" (2008, p. 132); el rostro, como el nombre, sella categorías y remite a un concepto y a una forma que se inscriben como mal, porque el rostro no solo impide el traspaso de fronteras entre las diferentes posibilidades que nos constituyen y nos habitan, sino que además potencia y magnifica el centramiento en el egotismo del yo. Monti es en este sentido fundamental como fuerza señera, subjetiva y de contagio. La relación entre él y el protagonista está traspasada por el afecto mutuo y por la admiración del segundo por el primero, pero también por la envidia y el desconcierto. Monti siempre va un paso más adelante que su amigo; cuando el protagonista de la novela lo reencuentra tras unas vacaciones escolares y lo ve con el peinado afro de moda, besando a la chica de los mocasines rojos que fue su novia en la infancia, comprende la disparidad en la que se funda su amistad, la lejanía radical que los separa: "Él comprende que su amigo siempre irá mucho más lejos que él, siempre más a fondo. ¿No es eso acaso un sobreviviente? ¿Alguien con quien es imposible medirse?” (37). El protagonista alcanza a ver un ángulo del rostro de la chica de los zapatos rojos y observa dos detalles que se fijan en su memoria: los dedos de ella escarbando en la maraña de rulos que su amigo ostenta y la celeridad de los besos que se dan, los que exhiben una vida experimentada en la velocidad permanente y que señalan su naturaleza anormal, su condición de figura de borde, de outsider con el que se entra en alianza en el proceso del devenir:

Lo anormal sólo puede definirse en función de caracteres, específicos o genéricos; pero lo anormal es una posición o un conjunto de posiciones con relación a una multiplicidad. Los brujos utilizan, pues, el viejo adjetivo anormal para situar las posiciones de un individuo excepcional en la manada. Para devenir animal, uno siempre hace alianza con el anormal. (Deleuze y Guattari, 2000, p. 249) 
Mientras el protagonista se atormenta con el recuerdo de la chica de los mocasines rojos, Monti ya se ha alejado de ese punto, la ha dejado embarazada y busca los medios para que ella pueda abortar. Esta propiedad de Monti, su capacidad para sortear situaciones y vivir siempre al límite, define en gran medida el devenir del protagonista, quien es arrastrado hacia una involución que lo va alejando paulatinamente de un rostro reconocible. La época, la transgresión, la celeridad, la precariedad y la amenaza de la muerte se inscriben en forma de huellas en su cuerpo. Cada vez que Monti aparece como un fantasma del pasado en la vida del protagonista es prácticamente irreconocible en los cambios físicos que experimenta: “¡No hace más que cambiar! Podría incluso ser un impostor, un impostor profesional" (88). Cada episodio biográfico de Monti, las facetas y torsiones que experimenta su recorrido vital a lo largo de la novela, se inscribe como una marca que afecta su cuerpo y que el protagonista atestigua en cada reencuentro. Y el pelo - lo que este evidencia y lo que se esconde tras él- es la huella de su trayecto. Monti se presenta en la narración siempre con ribetes transgresores; incluso, en la época escolar, participa en el robo de un auto y es condenado a un mes en un instituto de menores. El protagonista va a visitarlo cuando es procesado y descubre que lo han rapado; lo único que reconoce en él es la avidez inocente de sus ojos y su sonrisa, mientras que su cráneo evidencia infinidad de pequeñas cicatrices, “[...] una serie de rayas y de muescas [que] parecen trazar un dibujo secreto" (67). Estas marcas son luego disfrazadas con el pelo que vuelve a crecerle y que cambia desde el peinado afro, y la gomina que luego lo domeña, hasta el color blanco refulgente que después lo cubre y que se ve amenazado con la sorpresiva noticia que su amigo le espeta cuando vuelven a encontrarse en la calle; que su mujer, la madre de sus cuatro hijas, quiere separarse de él: “¿Podés creer? Justo ahora, que las nenas están por entrar a la escuela y a mí me descubren un cáncer. ¡Bingo!” (130). La aparición del problemita del pelo se presenta en la vida del protagonista de la novela de Pauls de forma intempestiva, como aparece luego la preocupación por la muerte; es el pelo lo que asemeja ambas experiencias y adquiere una magnitud desconocida: 
No descubre una experiencia sino una dimensión; no algo que su vida no hubiera incluido hasta entonces: algo que ya estaba en él, trabajándolo en silencio, con una paciencia de rumiante, a la espera del momento oportuno para despertar y emitir los primeros signos de una vida visible. La muerte es un ejemplo clásico. Se sabe que hay muerte como se sabe que el destino de todo cuerpo es caer o que el agua se vuelve vapor a una temperatura determinada. Es algo que se da por sentado: una certidumbre invisible, administrada a diario y en dosis tan infinitesimales que pierde consistencia, se confunde con el continuo de la vida y termina por pasar inadvertida. Así años. Hasta que de golpe aparece y reclama lo suyo. (19)

El problema de la muerte se presenta con la noticia del cáncer que afecta a Monti y es entonces cuando el pelo se convierte explícitamente en la huella de la enfermedad y establece una demarcación política como rasgo de una vida irreconocible, singularizada por la falta de certezas ante el porvenir. Este rasgo está contagiado del oscuro futuro que habitan los animales, también poseedores de una temporalidad incierta, e indica la imposibilidad de discernir entre el bios

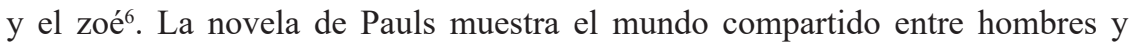
animales a través de la presencia de Curtius, el perro que comparte con Eva, su mujer. El protagonista ya ha conocido azarosamente a Celso, el peluquero paraguayo, quien ha logrado en él el corte perfecto y, por primera vez, la felicidad de adquirir un rostro que lo satisface:

Es un genio. No se lo dice, naturalmente. Pero aun sin articular, informe y engañoso, ése es el veredicto que oye sonar en alguna parte de su cabeza mientras asiente frente al espejo y aprueba lo que Celso está mostrándole, y es el júbilo ardiente y sobre todo desconocido que le inspira la cara que ve en el espejo lo que trata de contrarrestar ahora sofocando la sonrisa que se le insinúa en los labios. (75)

El protagonista de Historia del pelo, a diferencia de Monti, quien siempre surge con un rostro distinto, busca infatigablemente la tranquilidad de poseer un rostro que lo sitúe y lo inmovilice. Y el pelo, como marco de ese rostro, siempre está sujeto al cambio, al crecimiento, a su eventual caída, al cambio en el color y en la textura, a las alteraciones a las que lo somete el paso del tiempo y los accidentes de la vida. Nada presagia el arte de Celso; cuando el protagonista 
lo ve la primera vez, el peluquero barre los mechones de pelo que yacen en el suelo de la peluquería y le llaman la atención su aspecto de físicoculturista y la melena larga y debilitada por la desnutrición y los productos de bajo costo con los que probablemente se lava. Sin embargo, comienza a cortarle el pelo y el rumor casi imperceptible de las tijeras en su cabeza y la infinitesimal delicadeza, mezcla de aparente lentitud y de velocidad, con que va desgajando mechones para someterlos al prodigio lo hace pensar que quizás ni siquiera le está cortando el pelo. El detalle microscópico "[...] de las hebras finísimas, individuales, que parecen haber sido cortadas de a una" (72) sobre sus hombros y en el suelo confirma que efectivamente le han cortado el pelo. Pero Celso no solo consigue el milagro del corte perfecto, sino que además, al despedirse, le dice que lo espera en un mes y con eso le señala algo fundamental: la temporalidad del corte perfecto, la temporalidad y fragilidad de la felicidad: "Diez minutos más tarde, mientras atraviesa la ciudad como sedado, con los párpados que le pesan, se da cuenta: es la primera vez que un peluquero le revela el horizonte de vida de un corte" (77).

Los personajes de Pauls transitan en un devenir que los acerca a la muerte y en el que los animales, como señalan Deleuze y Guattari, no poseen una importancia exclusiva, sino que más bien son “[...] segmentos que ocupan una región media. Más allá encontramos devenires mujer, devenires niño [...] Más allá todavía, encontramos devenires elementales, celulares, moleculares, e incluso devenires imperceptibles" (2000, p. 253). El protagonista de Historia del pelo, extasiado ante su nueva imagen tras el corte de Celso, seguro de haber logrado la perfección, olvida ir a buscar al lavadero a Curtius, su perro, al que también le han cortado el pelo. El perro está ahora irreconocible y el corte le ha provocado, además, pequeñas heridas en diferentes lugares del cuerpo, que el protagonista detecta cuando lo acaricia y lo examina. El perro, en una curiosa reacción, mezcla de complacencia, dolor y pudor ante la exhibición de sus heridas, muerde una mano del protagonista; su mujer lo cura y esgrime una posible explicación al hecho:

Por ahí no te reconoció, dice, extrañada. Él la mira sin entender. Por el corte de pelo, digo, explica ella. ¿El mío o el de él?, pregunta él un poco escandalizado [...] Los dos, dice ella. Cuando los bañan o 
les cortan el pelo, los perros pierden el olor, su propio olor, y no se reconocen a sí mismos. Se psicotizan. Y vos, encima, que acabás de cortarte. ¿No viste qué raro se estuvo portando Curtius desde que fuiste a la peluquería? (83)

El perro le enrostra especularmente al protagonista su nueva imagen, desconocida, anómala. El nuevo rostro es otra máscara más, un nuevo disfraz, una nueva apariencia que por primera vez no lo atormenta. Pero el pelo, aparentemente una nimiedad, encierra algo siniestro que el protagonista descubre cuando Monti, el amigo al que reencuentra, le dice que está enfermo de cáncer al pulmón. Los hechos se precipitan con la búsqueda de la peluca mítica de la guerrillera implicada en el secuestro de Aramburu y conecta a los cuatro personajes en un recorrido individual y solitario marcado por la fragilidad, la que refiere una época precaria, que no ofrece respuestas para la soledad que los atraviesa. El protagonista experimenta el abandono y opta por el paulatino desasimiento de aquello que lo conectaba al mundo. Su mujer y Curtius se han ido, dejando el departamento prácticamente desmantelado, y él descubre que “[...] nunca ha sufrido menos. Hay en esa condición álgida que abraza un alivio extraordinario, un milagro anestésico que no sabría cómo pagar" (191). Y su recorrido se intersecta en ese momento con el del veterano de guerra por misteriosas vías, comiendo en un tenedor libre y buscando desesperadamente a Celso, quien ha desaparecido en los suburbios y ahora se dedica al shaving, para que él le proporcione las respuestas que busca a un conflicto que excede su problema con el pelo y que abarca su vida entera, todo lo que él ha depositado en el pelo como marca de sí mismo. El veterano de guerra, un "fantasma de fantasmas" (187), hijo de un héroe de la resistencia muerto cuando él era un niño, vive exiliado en París hasta que regresa a Buenos Aires a encontrar y perder su lugar en el mundo; vive en Buenos Aires gracias a lo mismo que le permitía subsistir en Francia: el comercio de drogas. El anonimato que exige su oficio, y que es una virtud mientras vive en París, se vuelve perturbador en su país. Tras la calurosa acogida que le otorgan a su llegada los antiguos amigos de sus padres, quienes lo reciben al principio con los honores que merece un sobreviviente, viene el desconcierto de tornarse 
[...] demasiado invisible. Como si la inmunidad que consigue a fuerza de tacto, perspicacia y un dominio pleno del idioma de sobreentendidos que exige la compraventa, velara cualquier signo capaz de delatar lo que hace pero sofocara también, al mismo tiempo, todo lo que él es, su identidad personal, su presencia en el mundo. Si es que tiene alguna, como se le da por preguntarse hace unos meses. (164)

El veterano de guerra experimenta una pérdida de corporeidad, de visibilidad y de identidad progresivas. Se relaciona con gente, asiste a fiestas, es objeto de una solidaridad engañosa y extraña, y siempre tiene la sensación de que está perdiendo su condición primera en la medida en que va despojándose de una "categoría con forma humana $[. .$.$] Y le parece que todas esas personas que$ ve comer, reírse, discutir, incluso bailar o besarse, o emborracharse están todas muertas" (166). En ese estado involutivo, fantasmagórico, se cruza con Celso, otro fantasma, otro habitante del mundo marginal, quien lo salva, sin un motivo claro, de una eventual golpiza o hasta de la muerte una noche en la que ambos coinciden en una discoteca a la que el veterano llega a deshacerse de la droga que todavía le queda por vender. Así descubre por accidente una sesión de shaving que se lleva a cabo en el subterráneo del lugar, sesiones en las que Celso desperdiga su arte. El veterano ha recibido como herencia de su padre la misteriosa peluca de Norma Arrostito, la peluca verdadera, disfraz o pantomima y símbolo real de una historia que no le pertenece, que fue la de su padre, y que Celso le roba, probablemente para costear un pasaje que le permita viajar a Brasil y perderse definitivamente allí. Celso deja como señal de su desaparición definitiva, como rastro de su huida, una nota donde le indica al veterano de guerra que el loco del pelo tiene su peluca. Y así se encuentran ambos personajes, unidos por un postizo que se refiere a la gran historia política de Argentina, un objeto que ni siquiera es posible tasar, porque el dolor, el mito, la utopía no tienen precio en el presente de la narración. Ese gran relato de la violencia no tiene cabida en la actualidad, es una historia tan artificial como el pelo verdadero del protagonista. La realidad y la fachada se confunden, pero la respuesta a qué elemento constituye la verdad, la única verdad asible y digerible, la entrega la botella de Ye Monks, regalo del padre del protagonista a su hijo, y que el veterano de guerra encuentra cuando pasa una 
noche en su departamento. Los dos discursos, el de la historia de la violencia argentina durante el proceso dictatorial de los setenta y el de la frivolidad que representa un objeto de culto, tan mítico como la peluca, se confrontan. Ninguna de las dos historias, la mayúscula que encierra la peluca y la minúscula que representa la botella, tiene precio:

Nada le resulta más desatinado que la idea de poner la peluca en un platillo de la balanza y dinero, no importa cuánto, en el otro. No hay equivalencia posible. Sin embargo, se imagina una botella de Ye Monks en lugar del dinero, una botella nueva, llena, y no le extraña que la balanza quede quieta, perfectamente estable. (184)

El final de la novela marca un abandono definitivo del mundo de las relaciones significantes, incluido su pelo. El protagonista, alertado por una excompañera de colegio, visita a Monti en la clínica. El amigo, pálido y demacrado, con una sonrisa burlona en la boca recibe la quimioterapia en uno de sus brazos desnudos. Está allí también la chica de los mocasines rojos, quien duerme en un sillón a su lado, traspasando el tiempo y las huellas que este va dejando:

El tratamiento se ha llevado ya la mitad de las cejas. Ha dejado dos rayitas truncas, horizontales, sin canas, que se recortan nítidas sobre la piel pálida, como un maquillaje japonés. Se pregunta cuánto tiempo deberá pasar hasta que el pelo se les una, cuánto hasta que las marcas secretas de la cabeza vuelvan a ver la luz. (193)

Las huellas de la época y de cómo somos afectados por ella, ya se trate del gran relato histórico o del pequeño relato político que se inscribe en el cuerpo, están ahí, ocultas a ratos, pero esperando su momento de desagravio para reaparecer. El presente se ofrece despojado y el futuro es incierto. La amenaza de la muerte inscrita en el pelo, la frivolidad de un período que remite a combates postizos, ajenos y artificiales que puede leerse en el pelo como en cualquier otro rasgo físico, revela lo único cierto, la realidad de la finitud. Y la esperanza marcada en la sonrisa burlona de Monti, un sobreviviente, parece dar la respuesta: el artificio es necesario, la verdad y la apariencia son visiones de lo mismo o se confunden en el relato autoficcional de un yo que se descubre y reconoce en 
el despojo. El retorno es imposible, tanto al relato heroico de una lucha que es extemporánea a los personajes de la novela de Pauls y que parece esconder los dolores individuales en un relato colectivo, al que remite la peluca verdadera de Arrostito, como a la ingenuidad de una vida que ya está signada por la soledad y el escepticismo, el pelo verdadero, el disfraz del protagonista, como él mismo le señala al veterano de guerra cuando este último viene a reclamar la herencia de su padre: “¿O te creés que esto puede ser pelo verdadero?” (152). El pelo solo esconde la verdad desnuda de los hechos, los verdaderamente importantes que la muerte enrostra:

El pelo, no importa a qué inclemencias se someta, sople viento, llueva o truene, emerja del fondo del mar o de doce horas de sueño, siempre queda peinado, el pelo de Michael Sarrazin, de Warren Beatty, de Kurt Russel, de Clint Eastwood, de cientos de rostros de la década que, más o menos célebres y respetables, jamás harán olvidar lo único que no debe ser olvidado: que la patria de ese corte es Argentina y que la época en que florece es la época en la que todo lo que nace y crece de la tierra es hijo de los ríos de sangre que reemplazan a los abonos tradicionales de que se nutre la tierra. (154)

La época y los rostros de una época se esconden en el relato que el cuerpo señala en su desnudez. La involución y el alejamiento del propio rostro surgen como la única solución posible para comprender esa realidad que la muerte señala en el cráneo marcado de Monti y entonces el protagonista comprende lo que debe entregarle a su amigo, lo que sabe que debe darle desde la última vez que lo vio. Se dirige a una peluquería cualquiera y pide que lo rapen, y que no tiren su pelo, porque se lo llevará para dárselo a su amigo, el sobreviviente de una batalla que exige ese disfraz para recuperar la ilusión, una de las huellas que el cuerpo exhibe a ratos y que a veces borra, pero donde habita la esperanza de la vida.

\section{Agradecimientos}

Este artículo fue escrito dentro del marco del proyecto Fondecyt Regular n. ${ }^{\circ} 1171250$, "El problema de los animales en las escrituras del yo latinoamericanas de las últimas décadas". 


\section{Notas}

1 A continuación, todas las citas de Historia del pelo llevarán solo número de página y corresponden a la edición citada en las referencias bibliográficas.

2 Jacques Rancière señala que la política de la literatura es el despliegue de los signos inscritos incluso en las cosas y que uno de sus regímenes consiste en "[...] hacer aparecer el universo de la realidad prosaica como un inmenso tejido de signos que lleva escrita la historia de una era, de una civilización o de una sociedad" (2011, p. 32).

3 John Berger plantea y desarrolla esta demarcación en “¡Por qué miramos a los animales?" en su libro Mirar (2001).

4 Jorge Monteleone observa, a propósito de la novela de Pauls, que "[...] la sorpresiva peluca del final, vinculada al secuestro de Aramburu, revela que nada, ni la insignificancia, puede sustraerse a la historia política, ni a la violencia ni a la tragedia" (2010, snp).

5 Las escrituras del yo incluyen textos autobiográficos y autoficcionales, e involucran un elemento testimonial muchas veces ficticio, porque lo verdaderamente importante en ellos no es la correspondencia entre realidad y ficción, sino la definición de un yo "[...] como elemento inestable y transitorio que se posiciona frente a los discursos de poder" (Jirku y Pozo, 2011, p. 13).

6 Gabriel Giorgi (2014) se refiere a la distinción entre humano y animal, la que se ha establecido históricamente en términos ontológicos; así, plantea una diferencia que debe pensarse más bien en términos biopolíticos: bios (persona) y zoé (no persona). Esta distinción es para Giorgi siempre móvil y desplaza su eje central constantemente.

\section{Referencias bibliográficas}

Adriaensen, B. (2017). Entre el escepticismo y la autenticidad. Dimensiones afectivas y políticas en Historia del llanto de Alan Pauls. HeLix - Dossiers zur romanischen Literaturwissenschaft, 10, 55-67. doi: 10.11588/ helix.2017.0.42023.

Agamben, G. (2006). Lo abierto. El hombre y el animal. Buenos Aires: Adriana Hidalgo.

Alberca, M. (2007). El pacto ambiguo. De la novela autobiográfica a la autoficción. Madrid: Editorial Biblioteca Nueva.

Bachelard, G. (2000). La poética del espacio. Buenos Aires: Fondo de Cultura Económica de Argentina.

Berger, J. (2001). Mirar. Barcelona: Editorial Gustavo Gili. 
Borges, J. L. (1980). Ficciones. Madrid: Alianza Editorial

Coetzee, J. M. (2005). Elizabeth Costello. Buenos Aires: Mondadori.

Deleuze, G. y Guattari, F. (2000). Mil mesetas. Capitalismo y esquizofrenia. Valencia: Pretextos.

Derrida, J. (2008). El animal que luego estoy si(gui)endo. Madrid: Editorial Trotta.

Echeverría, E. (2000 [1871]). El matadero. Alicante: Biblioteca Virtual Miguel de Cervantes. Recuperado de http://www.cervantesvirtual.com/nd/ ark:/59851/bmcgh9f3.

Giorgi, G. (2014). Formas comunes. Animalidad, cultura, biopolitica. Buenos Aires: Eterna Cadencia Editora.

González, C. (2017). Diálogos entre arte e historia argentina reciente en Ezeiza paintant de Fabián Marcaccio y la trilogía de los 70 de Alan Pauls. Anclajes, 21(1), 1-20. doi: 10.19137/anclajes-2017-2111.

Jirku, B. \& Pozo Sánchez, B. (2011). Escrituras del yo: entre la autobiografía y la ficción. Quaderns de Filologia. Estudis literaris, 16, 9-21. Recuperado de https://ojs.uv.es/index.php/qdfed/article/view/3944/3585.

Logie, I. (2013). A la búsqueda de un lugar de enunciación apropiado: la década de los setenta argentinos en Historia del llanto de Alan Pauls. En Memorias en tinta: ensayos sobre la representación de la violencia política en Argentina, Chile y Perú (164-180). Santiago: Ediciones Universidad Alberto Hurtado.

Mann, T. (1951). La montaña mágica. En Obras completas. Novelas. Barcelona: José Janés Editor.

Orecchia, T. (2013). Apuntes sobre el territorio y la creación: vidas de Alan Pauls. Cuadernos LÍRICO, 9, 1-19. doi: 10.4000/lirico.1153.

Pauls, A. (1984). El pudor del pornógrafo. Barcelona: Editorial Anagrama.

Pauls, A. (1994). Wasabi. Barcelona: Editorial Anagrama.

Pauls, A. (2003). El pasado. Barcelona: Editorial Anagrama.

Pauls, A. (2007). Historia del llanto. Barcelona: Editorial Anagrama. 
Pauls, A. (2010). Historia del pelo. Barcelona: Editorial Anagrama.

Pauls, A. (2013). Historia del dinero. Barcelona: Editorial Anagrama.

Pimentel, L. A. (2005). El relato en perspectiva: Estudio de teoría narrativa. Ciudad de México: Siglo Veintiuno Editores.

Rancière, J. (2011). Política de la literatura. Buenos Aires: Libros del Zorzal.

Varda, A. y Varda, A. (1968). Black panther newsreel [Cinta cinematográfica]. Francia: Coproducción Francia-Estados Unidos, Ciné Tamaris.

Yelin, J. (2008). Nuevos imaginarios, nuevas representaciones. Algunas claves de lectura para los bestiarios latinoamericanos modernos. LL Journal, 3(1), 1-12. Recuperado de https://journals.openedition.org/lirico/1153. 